\title{
RELATIVE FITNESS OF GENOTYPES IN A POPULATION OF RATTUS NORVEGICUS POLYMORPHIC FOR WARFARIN RESISTANCE
}

\author{
G. G. PARTRIDGE \\ Department of Genetics, University of Liverpool, Liverpool L69 3BX*
}

Received 11.iii.79

\begin{abstract}
SUMMARY
Resistance to warfarin and an increased vitamin $\mathrm{K}$ requirement appear to be pleiotropic effects of the same allele $\left(R w^{2}\right)$. In a natural population containing resistant individuals where the use of warfarin is discouraged the change in the frequency of resistance should reflect the relative fitnesses of the three possible genotypes.

A large polymorphic population of rats was extensively poisoned with warfarin and the level of resistance monitored regularly for a period of 18 months after withdrawal of the poison. During this period the proportion of resistant animals in live-capture samples decreased significantly from approximately 80 per cent to 33 per cent. This decline is consistent with a hypothesis of reduced fitness of both $R w^{2} R w^{2}$ and $R w^{1} R w^{2}$ genotypes relative to $R w^{1} R w^{1}$ under natural conditions. The relative fitnesses of these genotypes were calculated using an optimisation method based on least squares analysis. These estimates were: $R w^{2} R w^{2}(0.46), R w^{1} R w^{2}(0.77)$ and $R w^{1} R w^{1}(1 \cdot 00)$. Homozygous resistant individuals were found in some of the samples, confirming that the $R w^{2}$ allele does not act as a recessive lethal, although it must be extremely disadvantageous.

Some heterogeneity was observed in the proportion of resistant animals in samples taken from different areas of the farm building complex. This could reflect stochastic processes influencing the $R w^{2}$ allele frequency in small peripheral populations.
\end{abstract}

\section{IntRoduction}

THE anticoagulant rodenticide warfarin was introduced into Britain in 1953 (Greaves, 1971). The poison was used extensively to control rats and mice and was so successful that by 1961 half of the local authorities in England and Wales were using only warfarin in their rodent control programmes (Drummond, 1970). Inevitably rodent populations evolved genetically determined resistance to its effects. Resistance was found in brown rat populations from Scotland in 1958 and the English-Welsh border region in 1959.

Resistance is a dominant character controlled by a single autosomal gene $R w^{2}, R w^{1}$ being the normal susceptible allele (Greaves and Ayres, 1967). The Scottish and Welsh resistance phenotypes appear to differ in that the former shows incomplete penetrance in the heterozygote, while the latter is a completely dominant trait. The two forms of resistance may be due to different alleles at the same locus (Greaves and Ayres, 1976).

Hermodson, Suttie and Link (1969) found that, compared to susceptible animals, homozygous and heterozygous resistant rats had a twenty-fold and

* Present address: Department of Applied Nutrition, Rowett Research Institute, Bucksburn, Aberdeen AB2 9SB.

$43 / 2-F$ 
two-fold increase in vitamin $\mathrm{K}$ requirement respectively. In the absence of sufficient dietary vitamin, therefore, the homozygous resistant animal suffers from haemorrhagic disorders resulting from abnormally low levels of the vitamin $\mathrm{K}$-dependent blood clotting factors. The resistance allele maps at approximately the same site as an allele controlling a recessive haemorrhagic trait (Dunning and Curtis, 1939; Greaves and Ayres, 1969). It seems, therefore, that resistance to warfarin and an increased vitamin $\mathrm{K}$ requirement are pleiotropic effects of the same gene.

$\mathrm{F}_{2}$ matings of brown rats in the laboratory produced a deficiency of resistant male progeny, which could have been due to selective death of the $R w^{2} R w^{2}$ genotype (Bishop, Hartley and Partridge, 1977). At 8 weeks of age, $F_{2}$ litter size was significantly smaller than backcross litter size $(6 \cdot 16 \pm$ $2 \cdot 50$ cf. $8 \cdot 73 \pm 2 \cdot 41$, mean \pm s.d. $P<0 \cdot 01$ ).

In a natural population of resistant rats subjected to selection with warfarin, most animals would be expected to be heterozygotes, the segregating homozygotes of both types being eliminated. If warfarin is witheld the decline in the proportion of resistant animals should reflect the relative fitnesses of the three genotypes. This simplistic model can only be applied to a field situation when something is known of the population dynamics of the rats. The present paper attempts to estimate the relative fitnesses of the three possible genotypes of the $R w$ allele in a population containing resistant rats whose ecology is at least partially known (Bishop and Hartley, 1976; Hartley, 1977).

\section{Methods}

The population of rats investigated, which at the outset contained about 500 individuals, was within the building complex of a mixed poultry and dairy farm (Upper Min-y-llyn) near Welshpool, Powys. The relationship between this farm-building population and the surrounding hedgerow populations has been described elsewhere (Bishop and Hartley, 1976).

My experiment raised the level of phenotypic resistance by poisoning the building population with warfarin baits in April and June 1976. No bait trays were positioned in the surrounding hedgerows where rats were known to be present. The proportion of resistant rats was then observed in samples subsequently taken from the population at regular intervals from September 1976 to April 1978. The use of warfarin for rodent control was discouraged throughout this period. Prior to warfarin poisoning the level of resistance was determined in a live-capture sample of rats from the buildings. These and all subsequent animals were phenotyped by the vitamin $\mathrm{K}$ oxide/ warfarin injection method (Bishop et al., 1977). The genotypes of resistant animals in several samples were determined by the method of Greaves, Redfern, Ayres and Gill (1977). This method was tested independently at Liverpool, and gave adequate separation of the $R w^{2} R w^{2}$ and $R w^{1} R w^{2}$ genotypes (Partridge, 1978).

On each sampling occasion approximately 30 traps were set for three consecutive nights. Multiple capture traps were set in areas of high rat infestation. All animals were weighed, sexed and marked on capture (Bishop and Hartley, 1976) and on return to the laboratory they were acclimatised for at least 3 weeks before being phenotyped. One week later the genotypes of resistant animals were determined. 


\section{Results}

Table 1 shows the proportion of resistant animals in samples taken from the farm buildings between February 1976 and April 1978 The level of resistance in the pre-warfarin treatment sample (February, 1976) was clearly very low, continuing the trend noted in the preceding years (Bishop et al., 1977, table 4). Following warfarin poisoning in April 1976 the frequency of resistance rose significantly in the June sample $(P=0.0001$, Fisher's exact test, one tail). The population size, reflected by the total numbers caught in each period of similar sampling intensity, was small at the end of 1976 but thereafter became much larger.

\section{TABLE 1}

The number of warfarin resistant rats in samples taken from the Upper Min-y-llyn farm buildings from February 1976 to April 1978. For samples prior to February 1976 see Bishop et al. (1977, table 4)

\begin{tabular}{|c|c|c|c|c|c|}
\hline & $\mathrm{Da}$ & of sample & Resistant & Susceptible & $\begin{array}{c}\text { Estimated \% } \\
\text { resistant }( \pm \text { s.e. })\end{array}$ \\
\hline 1976 & Feb. & & 0 & 61 & 0 \\
\hline & $\begin{array}{l}\text { Apr. } \\
\text { Iun. }\end{array}$ & Warfarin treatment & 5 & 8 & $38 \cdot 5+13 \cdot 5$ \\
\hline & Jun. & Warfarin treatment & & & \\
\hline & Sep. & & 2 & 0 & 100 \\
\hline & Nov. & & 12 & 0 & 100 \\
\hline 1977 & Feb. & & 22 & 8 & $73 \cdot 3 \pm 8 \cdot 1$ \\
\hline & May & & 45 & 20 & $69.2 \pm 5.7$ \\
\hline & Aug. & & 26 & 25 & $51 \cdot 0 \pm 7 \cdot 0$ \\
\hline & Dec. & & 12 & 13 & $48 \cdot 0 \pm 10 \cdot 0$ \\
\hline 1978 & Apr. & & 11 & 22 & $33.3 \pm 8.2$ \\
\hline
\end{tabular}

An examination of the age structure of animals caught in the samples from June 1976 to August 1977 revealed that the population bred throughout the period. This contrasts with the surrounding hedgerow populations which undergo periods of reproductive quiescence (Bishop and Hartley, 1976).

There is significant heterogeneity in the proportion of phenotypic resistance over the sampling periods from November 1976 to April 1978 (table 1). There was a consistent decline in resistance over this 18-month period, from a high level (80-100 per cent) to a much lower level (around 33 per cent). The data were re-assigned according to the age structure of individual samples as this was more suitable to the discrete generation model which was used to estimate selection coefficients.

Young male and female wild brown rats increase in weight by approximatley $61 \mathrm{~g}$ and $52 \mathrm{~g} /$ month respectively (Bishop and Hartley, 1976). Animals in a sample weighing more than $200 \mathrm{~g}$ could therefore be reassigned to the preceding sampling period, which was usually 3 months earlier. No animals were re-assigned beyond the preceding trapping period. Movements of hedgerow rats into the farm buildings were negligible (Bishop and Hartley, 1976; Hartley, 1977) and consequently immigration was unlikely to affect re-assignment of the data. Similarly, old animals losing weight before death (Bishop and Hartley, 1976, p. 630) were unlikely to be mis-classified as they were easily recognised by their poor body condition.

Breeding studies indicated that selection against $R w^{2} R w^{2}$ animals takes 
place from birth to at least 8 weeks of age (Bishop et al., 1977). It is possible therefore that immature homozygous resistant rats could be lost from the population before reaching maturity $(<200 \mathrm{~g})$. This was tested by comparing the frequency of the $R w^{2} R w^{2}$ genotype in the mature ( $>200 \mathrm{~g}$ ) and immature ( $\leqq 200 \mathrm{~g}$ ) weight groups, for each sample. Table 2 shows the genotypes of resistant individuals captured from September 1976 to August 1977. The sexes were tested separately because laboratory results had indicated that selection against resistant males might be stronger than that against females (Bishop et al., 1977). Seven animals died before genotyping, as indicated. The genotypes present in the two samples taken in December 1977 and April 1978 were not determined. Fisher's exact tests for each month indicate that the frequency of the $R w^{2} R w^{2}$ genotype does not differ between the sex/weight groups. This implies, in contradiction to the laboratory studies (Bishop et al., 1977), that any selection against the $R w^{2} R w^{2}$ genotype under natural conditions is over before animals reach the trappable population (around $50 \mathrm{~g}$ body weight). This could be because the natural environment selects more vigorously against suckling animals $(<50 \mathrm{~g})$ than does the animal house environment.

Table 3 compares the original and re-assigned data. The December 1977 and April 1978 samples were not weighed on capture and no attempt has been made therefore to re-assign rats from these samples. Clearly the only major difference between the original and re-assigned estimates is for November 1976 (100 per cent versus 80 per cent). The latter figure is likely to be more realistic because it will be virtually impossible to kill all susceptible individuals in a large population using a standard poison treatment.

The complete re-assigned data (table 3, November 1976 to April 1978) were analysed by an optimisation computer program written by $\mathrm{Dr} R$. D. White which had been designed to deal with similar data for sheep blowflies resistant to insecticide (White, 1978). The optimisation procedure derives the best-fitting curve to the observed resistance phenotype frequency change by least squares analysis (Colquhoun, 1971, pp. 259-266). The fitness of both homozygotes relative to the heterozygote was iteratively adjusted by the optimisation routine so as to minimise the sum of squared deviations of the observed results from the fitted line. The population was assumed to be in Hardy-Weinberg equilibrium by November 1976 because there was time for breeding between poisoning in June and the first large sample in November. The fitness values obtained for the three genotypes were: $R w^{2} R w^{2}$ (0.5980), $R w^{1} R w^{1}(1 \cdot 2945)$ and $R w^{1} R w^{2}$ (assumed 1 $\left.\cdot 0000\right)$. Re-calculating these fitness values relative to the $R w^{1} R w^{1}$ genotype gives relative fitness estimates of $R w^{1} R w^{1}(1 \cdot 00), R w^{1} R w^{2}(0 \cdot 77)$ and $R w^{2} R w^{2}(0 \cdot 46)$.

Trapping records showed that certain areas of the farm buildings supported much larger rat populations than others. The farm-building complex was therefore approximately divided into six areas, according to their level of infestation. Two main criteria were used in this subdivision. Firstly, the frequency of captures in relation to "trap opportunities" and secondly, the spatial relationships between known foci of rat activity, i.e. the main food sources and buildings. In drawing these areas it is not implied that a population substructure exists; its main function is to subjectively divide the population and to compare the level of resistance from month to month within each area.

Table 4 shows the levels of infestation in the six designated areas. Most 


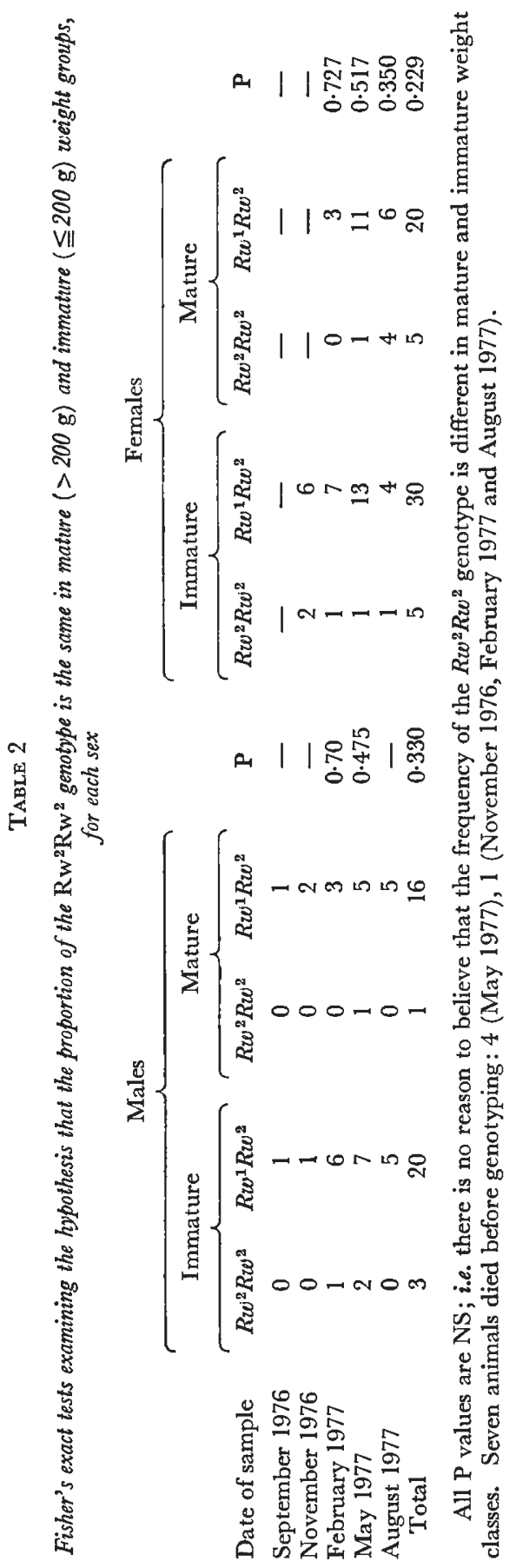


TABle 3

The proportion of resistant animals in samples from the Upper Min-y-llin farm buildings before and after re-assigning the data

\begin{tabular}{|c|c|c|c|c|c|c|}
\hline \multirow[b]{2}{*}{ Month } & \multicolumn{3}{|c|}{ Original data } & \multicolumn{3}{|c|}{ Re-assigned data } \\
\hline & Resistant & Susceptible & $\begin{array}{c}\% \text { Resistant } \\
\quad( \pm \text { s.e. })\end{array}$ & Resistant & Susceptible & $\begin{array}{c}\% \text { Resistant } \\
( \pm \text { s.e. })\end{array}$ \\
\hline November 1976 & 12 & 0 & 100 & 16 & 4 & $80 \cdot 0 \pm 8 \cdot 9$ \\
\hline February 1977 & 22 & 8 & $73 \cdot 3 \pm 8 \cdot 1$ & 37 & 13 & $74 \cdot 0 \pm 6 \cdot 2$ \\
\hline May 1977 & 45 & 20 & $69 \cdot 2 \pm 5 \cdot 7$ & 39 & 24 & $61 \cdot 9 \pm 6 \cdot 1$ \\
\hline August 1977 & 26 & 25 & $51 \cdot 0 \pm 7 \cdot 0$ & 11 & 12 & $47 \cdot 8 \pm 10 \cdot 4$ \\
\hline December 1977 & 12 & 13 & $48 \cdot 0 \pm 10 \cdot 0$ & \multicolumn{3}{|c|}{ Not re-assignable } \\
\hline April 1978 & 11 & 22 & $33 \cdot 3 \pm 8 \cdot 2$ & \multicolumn{3}{|c|}{ Not re-assignable } \\
\hline
\end{tabular}

areas appeared to have high levels of resistance by November 1976, following the second extensive warfarin treatment 5 months earlier. Thereafter the proportion of resistant animals in samples from all areas tended to decline. However, by August 1977 there is some apparent heterogeneity between the resistance levels in the large (II and III) and small (I, IV, V, VI) populations. Changes in the proportion of resistant animals in large populations should reflect natural selective processes. Peripheral populations, however, which fluctuate in size will be influenced by stochastic processes. Area $\mathrm{V}$, for example, did not appear to support a large population of rats from September 1976 to February 1977. The low level of resistance found in May and August 1977 (compared to areas II and III) could therefore be due to colonisation of the area by susceptible animals. The heterogeneity observed, whether real or a sampling artifact, illustrates that care must be taken when assigning selective values for the genotypes in natural populations. If the measured level of resistance was biased by nonselective effects then the calculated coefficients of selection would be subject to error.

TABLE 4

The phenotypes of animals caught in trap areas I to VI from September 1976 to August 1977 $($ Res. $=$ Resistant, Sus. $=$ Susceptible $)$. Areas $I I$ and III are associated with extensive food sources (poultry houses and grain silos), the other areas are peripheral to the main food sources

\begin{tabular}{|c|c|c|c|c|c|c|c|c|c|c|}
\hline \multirow{2}{*}{$\begin{array}{l}\text { Trap } \\
\text { area }\end{array}$} & \multicolumn{2}{|c|}{ Sep. 76} & \multicolumn{2}{|c|}{ Nov. 76} & \multicolumn{2}{|c|}{ Feb. 77} & \multicolumn{2}{|c|}{ May 77} & \multicolumn{2}{|c|}{ Aug. 77} \\
\hline & Res. & Sus. & Res. & Sus. & Res. & Sus. & Res. & Sus. & Res. & Sus. \\
\hline II & 1 & 0 & 4 & 0 & 12 & 4 & 9 & 5 & 5 & 6 \\
\hline III & 一 & - & 2 & 0 & 5 & 3 & 27 & 7 & 18 & 9 \\
\hline I & 1 & 0 & 2 & 0 & 2 & 0 & 7 & 3 & 1 & 1 \\
\hline IV & - & - & 一 & 一 & - & - & - & - & 1 & 1 \\
\hline V & - & - & - & - & - & - & 1 & 4 & 1 & 6 \\
\hline VI & - & - & 4 & 0 & 3 & 1 & 1 & 1 & 0 & 2 \\
\hline
\end{tabular}

$2 \times 2$ contingency tests examining the hypothesis that the frequency of resistance is the same in the heavily infested areas (II and III) as it is in the peripheral areas (I, IV, V and VI pooled) for August 1977.

Comparing :

Areas II and III : $\chi_{1}^{2}=0 \cdot 718 ; P=$ n.s.

Area II and the peripheral areas: $\chi_{1}^{2}=0.524 ; P=$ n.s.

Area III and the peripheral areas: $\chi_{1}^{2}=5 \cdot 052 ; \mathrm{P}<0.05$. 


\section{Discussion}

We were assured by the farmer that warfarin poison was not used during the sampling period and the results are consistent with this hypothesis. Difenacoum anticoagulant was used by the farmer in an abortive attempt to control rat numbers prior to the sample being taken in April 1978. Difenacoum is active against both warfarin resistant and susceptible animals, but its toxicity to the resistant animal is only half of that to the susceptibles (Hadler, Redfern and Rowe, 1975). After an inadequate treatment with this substance the level of resistance in the population in April 1978 could have been higher than anticipated.

The decline in the frequency of resistance observed in the Upper Min-yllyn farm buildings after withdrawal of warfarin supports the findings of other workers. Greaves et al. (1977) describe a study in which the level of resistance was compared between two areas in mid-Wales. Farmers in one relatively isolated valley were encouraged to avoid the use of anticoagulant poisons, while no such encouragement was given in the other areas. After problems of "illicit" selection with anticoagulants had been overcome the percentage of resistant rats in samples from the controlled valley decreased significantly over the next 2 years (from 57 per cent to 47 per cent to 39 per cent). In the uncontrolled areas the percentage of resistant animals fluctuated around a mean of 44 per cent, changes between years being insignificant. Relative fitness estimates for the three genotypes in the uncontrolled areas were: $R w^{2} R w^{2}(0 \cdot 37), R w^{1} R w^{1}(0 \cdot 68)$ and $R w^{1} R w^{2}$ (assumed 1.00).

The present study has the advantage that it was confined to an infestation of a single building complex whose relationships to smaller outlying hedgerow populations had already been determined (Bishop and Hartley, 1976, Hartley, 1977). The Welsh valleys experiment (Greaves et al., 1977) measured an overall response from a heterogeneous sample of populations of various sizes in different environments. This situation is therefore analogous to lumping the differences observed in resistance level between the hedgerow and building populations at Upper Min-y-llyn. The disparity in resistance level observed in these adjacent populations could be due to different dynamic processes operating within them (Bishop et al., 1977).

The detection of homozygous resistant individuals in the natural population (table 2) confirms that the $R w^{2}$ allele does not act as a recessive lethal. This agrees with the data of Greaves et al. (1977) who also found $R w^{2} R w^{2}$ individuals in their wild-caught samples. There was no significant difference in the proportion of homozygous resistant animals of each sex (table 2). Clearly therefore any sex differences in the viability of the $R w^{2} R w^{2}$ genotype are not marked under natural conditions. This contrasts with laboratory studies (Bishop et al., 1977) which had indicated that selection against $R w^{2} R w^{2}$ animals appeared to be more marked in males, possibly reflecting their greater vitamin $\mathrm{K}$ requirement (Partridge, 1978).

Despite the complexity of the ecogenetics of warfarin resistance (Bishop et al., 1977) the estimates of fitness obtained in this study and by Greaves et al. (1977) enable predictions to be made of the change in resistance frequency in a large polymorphic population of brown rats. With the advent of anticoagulant poisons which are active against warfarin-resistant rats (Hadler and Shadbolt, 1975) there is now the opportunity to use balanced rodenticide treatments in warfarin-resistant areas. In practical terms, 
however, the indiscriminate use of selective poisons will always be an insurmountable problem to the best-laid plans for control.

Acknowledgments.-I would like to thank officers of the Pest Infestation Control Laboratory, Tolworth, for help and advice during the study and Dr R. D. White (Department of Biology, University of Southampton) for the computer analysis of the data. Dr J. A. Bishop and Dr J. H. Greaves offered valuable criticism of the manuscript. Carol Keill provided technical assistance. The work was done while $I$ was in receipt of an S.R.C. research studentship.

\section{REFERENCES}

BISHOP, J. A., AND HARTLEY, D. J. 1976. The size and age structure of rural populations of Rattus norvegicus containing individuals resistant to the anticoagulant poison warfarin. 7. Anim. Ecol. 45, 623-646.

BISHOP, J. A., HARTLEY, D. J., AND PARTRIDGE, G. G. 1977. The population dynamics of genetically determined resistance to warfarin in Rattus norvegicus from mid-Wales. Heredity, 39, 389-398.

Colquhoun, D. 1971. Lectures on Biostatistics. Oxford University Press.

DRUMMOND, D. C. 1970. Variation in rodent populations in response to control measures. Symp. Zool. Soc. Lond., 26, 351-367.

DUNNING, W. F., AND CURTIS, M. R. 1939. Linkage in rats between factors determining a pathological condition and a coat colour. Genetics, 24, 70.

Greaves, J. H. 1971. Resistance to anticoagulants in rodents. Pestic. Sci., 2, 276-279.

GREAVES, J. H., AND AYRES, P. 1967. Resistance to warfarin in rats. Nature, 215, 877-878.

GREAVES, J. H., AND AYRES, P. 1969. Linkages between genes for coat colour and resistance to warfarin in Rattus norvegicus. Nature, 224, 284-285.

GREAVES, J. H., AND AYRES, P. 1976. Inheritance of Scottish-type resistance to warfarin in the Norway rat. Genet. Res. Camb., 28, 231-239.

GREAVES, J. H., REDFERN, R., AYRES, P., AND GILL, J. E. 1977. Warfarin resistance: a balanced polymorphism in the Norway rat. Genet. Res. Camb., 30, 257-263.

HADLER, M. R., REDFERN, R., AND ROWE, F. P. 1975. Laboratory evaluation of difenacoum as a rodenticide. F. Hyg., 74, 441-448.

HADLER, M. R., AND SHADBOLT, R. S. 1975. Novel 4-hydroxycoumarin anticoagulants active against resistant rats. Nature, 253, 272-277.

HARTLEY, D. J. 1977. Ecology and movements of brown rats (Rattus norvegicus) in rural populations containing individuals resistant to the anticoagulant poison warfarin. Ph.D. thesis, University of Liverpool.

HERMODSON, M. A., SUTTIE, J. W., AND LINK, K. P. 1969. Warfarin metabolism and vitamin $\mathrm{K}$ requirement in the warfarin resistant rat. Am. F. Physiol., 217, 1316-1319.

PARTRIDGE, G. G. 1978. The pleiotropic effects of the gene conferring warfarin resistance in the brown rat (Rattus norvegicus). Ph.D. thesis, University of Liverpool.

white, R. M. (1978. Ecological and population genetics of insecticide resistance in the Australian sheep blowfly, Lucilia cuprina. Ph.D. thesis, University of Liverpool. 